\title{
RECONSTRUCCIÓN HISTÓRICA DE LA PRODUCCIÓN DE CECINA DE EQUINO DE VILLARRAMIEL (PALENCIA): CAMINO HACIA LA CALIDAD
}

\author{
Julio Fernández Portela ${ }^{1}$ \\ Departamento de Geografía \\ Universidad de Valladolid
}

\section{RESUMEN}

La apuesta por la calidad en los productos agroalimentarios de Castilla y León ha sido una medida constante en las últimas décadas como un elemento diferenciador de sus productos. La proliferación de figuras de calidad ha sido muy elevada abarcando diferentes productos como las carnes, vinos, frutas, legumbres, etc. en las diversas provincias de la región. Esto a su vez, ha constituido un impulso en la economía de las áreas rurales con la aparición de nuevas actividades económicas.

El presente artículo tiene como finalidad realizar una reconstrucción temporal de la historia de la cecina de equino en la localidad palentina de Villarramiel. En él se pretende demostrar la importancia que este producto ha tenido en la economía de este municipio a lo largo del siglo XX, con especial incidencia a partir de los años cincuenta.

Palabras clave: figuras de calidad, cecina, cecina de caballo, tejido económico.

\section{ABSTRACT}

The commitment to quality in the food products from Castile and León has been a consistent measure in the last decades as a differentiating factor of its products.

1 Investigador del programa de Formación de Profesorado Universitario (FPU) del Ministerio de Educación del Gobierno de España.jfportela@geo.uva.es 
There has been a large proliferation of quality products within different sectors like meat, wine, fruit, vegetables, etc. from different provinces in the region. In turn, this has constituted an impulse in the economy of the rural areas with the emergence of new economic activities.

This study seeks to make a temporary reconstruction of the history of dried horse meat in Villarramiel Palencia. It aims to demonstrate the importance this product has had on the economy of this municipality during the 1900s, with special emphasis from the 1950s onwards.

Keywords: quality products, dried meat, dried horse meat, economic fabric

\section{INTRODUCCIÓN}

La industria agroalimentaria ha sido una línea de investigación de gran relevancia en las estudios de economistas y geógrafos principalmente durante las últimas dos décadas. En una comunidad autónoma como Castilla y León esta rama industrial adquiere mayor envergadura al ser uno de los principales motores económicos de la región, pero sobre todo del mundo rural con la aparición de numerosas instalaciones destinadas a la elaboración de carnes, quesos, vinos y aceite entre una amplia gama de productos. Todos estos productos han sido recogidos en diferentes obras que agrupan a los alimentos de calidad que hay en la región, destacando entre las más representativas Alimentos de calidad de Castilla y León (2002) dirigida por Casanova Todolí e Inventario de productos agroalimentarios de calidad de Castilla y León (2001) dirigida por Molinero Hernando.

Desde el punto de vista económico y territorial son numerosas las publicaciones que se están produciendo en este ámbito a cargo de diversos autores. Algunos departamentos de las facultades de economía y de las escuelas de empresariales de las universidades de Castilla y León llevan trabajando en este campo varias décadas y han publicado diferentes libros, artículos e informes técnicos relacionados con este tema. Gordo Gómez $(1989,1990,2011)$ en sus diferentes obras recoge visiones generales de la industria agroalimentaria, la situación en cada uno de los diferentes periodos de tiempo, su distribución espacial, su peso económico en el conjunto regional y en el medio rural pero también en el contexto nacional y europeo. Los trabajos de Juste Carrión $(2002,2011)$ se centran más en el papel que juega la industria agroalimentaria en el desarrollo rural a través de su orientación hacia la elaboración de productos de calidad que permitan la competitividad y la supervivencia del mundo rural.

La calidad es un tema muy recurrente en este tipo de investigaciones, y las nuevas líneas se enfocan hacia el análisis de productos concretos que cuentan con alguna figura como Denominaciones de Origen (D.O.), Indicaciones Geográficas Protegidas (IGP) o Marcas de Garantía (MG) entre otras. Son numerosos 
los autores que trabajan en este tema destacando Gómez Arias y Bello Acebrón (1996), Pérez-Bustamante Ilander (1999) o De la Calle Robles (2002). Pero los estudios más recientes se están orientando hacia el análisis de los procesos de innovación de determinadas industrias, creación de redes, la entrada de capital exógeno o la gestión de la calidad de determinados productos destacando los vinos, pero también de las carnes, los quesos, la repostería y las frutas. Alonso Santos et al (2003), Sánchez Hernández (2003) y Aparicio Amador et al (2008) están trabajando en los procesos de innovación y figuras de calidad de la industria vitivinícola en Castilla y León. También son interesantes los trabajos que están desempeñando otros investigadores en otras regiones españolas en torno a estos temas como Jiménez Zarco y Gómez Borja (2002) en Castilla la Mancha y García Galán (2006) en Extremadura.

Dentro este contexto de industrias agroalimentarias y figuras de calidad se enmarca el artículo de la cecina de caballo de Villarramiel que se presenta a continuación, y cuyo objetivo es realizar una reconstrucción temporal de la historia de la cecina de equino en esta localidad palentina que permita ver la importancia económica que ha tenido en el municipio desde los años cincuenta hasta la actualidad.

\section{LAS FIGURAS DE PROTECCIÓN EN LOS ALIMENTOS: CALIDAD Y SEGURIDAD}

Las figuras de calidad constituyen un elemento diferenciador de los productos agroalimentarios de un determinado lugar que han ayudado a consolidar a la industria agroalimentaria como una actividad estratégica en la industria española al ser una de las ramas más importantes en el conjunto de la economía nacional (Fernández Barcala et al, 2001).

En el caso de Castilla y León las figuras de calidad han servido para distinguir una serie de productos de fuerte renombre y facilitar su distribución en el exterior de la región, a la vez que han actuado como soporte económico de un número muy importante de núcleos rurales. La calificación de un producto como Denominación de Origen, Indicación Geográfica Protegida o Marca de Garantía supone un fuerte impulso en su comercialización y puede acarrear unos incrementos económicos muy significativos.

La aparición de estas figuras en Castilla y León en las últimas décadas ha supuesto un nuevo aporte económico para algunos espacios rurales. En algunas ocasiones han contribuido a la creación de empleo, principalmente para personas jóvenes y mujeres, que han ayudado a mantener el paisaje agrario tradicional y han diversificado un medio rural caracterizado por la dominancia del sector agrícola. 
La obtención de una de estas figuras requiere unos requisitos de calidad, sabor, producción, etc. muy estrictos pero que una vez conseguidos pueden aportar prestigio al producto y un incremento en los beneficios económicos a los productores.

La lista de productos con alguna figura de calidad en Castilla y León es muy amplia y presenta una gran variedad que abarca sectores muy diversos como las carnes, los vinos, los quesos, las legumbres o las frutas. Pero esta lista se va incrementando poco a poco debido al enorme interés que han suscitado estos sistemas de calidad entre los consumidores, así como la aparición de otras asociaciones y marcas que contribuyen a la difusión y promoción de los productos como «Tierra de Sabor» o «Artesanos de Castilla y León».

El sector agroalimentario de la región constituye un pilar fundamental en la economía de un número muy importante de municipios rurales. La aparición de numerosas industrias ha ayudado a revitalizar el tejido económico de un medio rural caracterizado por la pérdida continuada de población, de actividades económicas y de envejecimiento. La pérdida de población en Castilla y León a lo largo de los últimos decenios ha sido constante y ha convertido a la región en un espacio abastecedor de recursos humanos a otros territorios más afortunados dentro y fuera del país (Caballero Fernández-Rufete et al, 2012).

Dentro de la industria agroalimentaria existe una gran variedad de productos que han ido consolidando a la región como un referente en la elaboración de alimentos de calidad, siendo el subsector vitivinícola una de las bazas esenciales en su consolidación como un mercado exigente de alimentos de calidad (Alonso Santos et al, 2003).

Las figuras de calidad son un distintivo utilizado para identificar y distinguir una serie de productos que presentan características especiales en el origen de su materia prima, en su elaboración y en su localización entre otros aspectos. Los criterios que se utilizan para establecer alguna de estas figuras de protección son diversos destacando los aspectos sanitarios, seguridad alimentaria, sabor o los métodos de producción tradicionales entre otros aspectos (De La Calle Robles, 2002).

Las principales figuras de calidad que existen en Castilla y León en orden de mayor a menor protección son las Denominaciones de Origen (D.O.), las Indicaciones Geográficas Protegidas (I.G.P.) y las Marcas de Garantía (M.G.).

Según el Reglamento (CE) 510/2006 del Consejo, de 20 de marzo de 2006, se define Denominación de Origen e Indicación Geográfica Protegida como «el nombre de una región, de un lugar determinado o, en casos excepcionales, de un país, que sirve para designar un producto agrícola o un producto alimenticio.» Los productos de las D.O. y las I.G.P. deben tener su origen en dicha región y 
la producción, transformación y elaboración se tiene que realizar en esta zona concreta. El criterio que las diferencia reside en que la D.O posee características exclusivas del medio geográfico donde se encuentra e incluyen los factores naturales y los humanos, mientras que las I.G.P. deben tener una cualidad determinada, una reputación o cualquier otra característica que pueda atribuirse a dicho origen geográfico.

Bajo las D.O. y las I.G.P. se ampara una parte muy significativa de los productos agroalimentarios que poseen alguna figura de calidad en la región, pero hay que tener en cuenta las «Marcas de Garantía», otro distintivo que también se utiliza para la diferenciación de estos productos.

Según el artículo 68 de la Ley 17/2001, de 7 de diciembre, de Marcas, se define Marca de Garantía como «todo signo susceptible de representación gráfica, (...), utilizado por una pluralidad de empresas bajo el control y autorización de su titular, que certifica que los productos o servicios a los que se aplica cumplen unos requisitos comunes, en especial, en lo que concierne a su calidad, componentes, origen geográfico, condiciones técnicas o modo de elaboración del producto o de prestación del servicio.»

Estas figuras constituyen un incentivo importante a la hora de adquirir un producto por parte de los consumidores. Los signos distintivos que poseen los alimentos confieren seguridad al cliente que poco a poco va depositando mayor confianza en un determinado producto de calidad por el que pagan un sobreprecio respecto a otros que no ofrece las mismas garantías (Fernández Barcala et al, 2001).

En total existen más de 252 productos agroalimentarios de calidad en Castilla y León que poseen unas características propias al ser elaborados de forma tradicional, por su historia, peculiaridades, tradición, costumbres, clima, suelo, etc. (Molinero Hernando et al, 2001) y 53 de ellos poseen alguna figura de protección.

Estos datos ponen de manifiesto la impronta que posee la industria agroalimentaria de calidad en la región, que lejos de estancarse, va adquiriendo cada vez más prestigio en el contexto regional y nacional con la promoción y difusión de sus alimentos. Un ejemplo significativo lo constituyen los nuevos proyectos que se están llevando a cabo para que otros productos de la tierra de Castilla y León puedan optar a alguna de estas figuras de calidad, siendo la cecina de caballo de Villarramiel uno de los últimos en intentar entrar en esta lista.

La idea de este proyecto surge a través de varios agentes, tanto públicos como privados, constituidos por la Asociación Promotora Empresarial de Villarramiel, el Ayuntamiento de la localidad, los productores de cecina, el Centro Tecnológico del Cereal (CETECE) y el Grupo de Acción Local Araduey-Campos. La financiación de este proyecto corre prácticamente en su totalidad (73\%) a 
cargo del Grupo de Acción Local de la comarca y el resto (27\%) lo aportan los tres productores que permanecen en el municipio. Su objetivo es la declaración de la «Marca de Garantía» para la cecina de caballo de Villarramiel, uno de los motores económicos del municipio desde los años 50 y 60 y que en la actualidad consigue sobrevivir a pesar de existir tan solo tres productores de los casi treinta que llegó a tener, a la vez que se consolida como un pilar básico del desarrollo rural de este municipio.

\section{REGRESIÓN EN LA TIERRA DE CAMPOS. EL EJEMPLO DE VILLARRAMIEL: ENVEJECIMIENTO Y DECADENCIA ECONÓMICA}

Villarramiel está ubicado en pleno corazón de la Tierra de Campos, uno de los espacios más afectados en Castilla y León durante la crisis agraria debido a la fuerte orientación agrícola y ganadera de la mayor parte de los municipios que componen este territorio.

Esta comarca se extiende en un $40 \%$ por la provincia de Palencia, casi un $37 \%$ en la provincia de Valladolid, un $18 \%$ en Zamora y un $4 \%$ en la de León.

El municipio de Villarramiel se localiza en la provincia de Palencia (ver figura 1) y posee una fuerte orientación agrícola, pero a diferencia de los municipios de su entorno también ha conseguido desarrollar un tejido industrial vinculado a los curtidos, a la cecina y los calzados que le permitió ser un centro de servicios de gran relevancia para su entorno más inmediato en los años 50 y 60. Desde entonces ha ido perdiendo peso debido al éxodo rural y se ha producido el cierre de establecimientos comerciales y la pérdida de efectivos demográficos.

Alrededor de esta industria se desarrolló un nuevo tejido económico empleando mucha mano de obra. Existieron más de treinta curtidores, más de veinte cecineros y un gran número de zapateros. La población tenía su pequeño taller en la cuadra de su casa y desde allí desempeñaba su trabajo, hasta que, poco a poco, se fue desmoronando gran parte de este entramado industrial a causa de la emigración.

Villarramiel llegó a tener casi 4.000 habitantes a comienzos del siglo XX. Desde entonces la población fue disminuyendo lentamente hasta 1940 y cayó bruscamente entre 1950 y 1980. Hasta 1980 la población había descendido en más de 2.500 personas respecto a la de 1900 y según el censo de 1981 era de 1.311 habitantes. La tendencia actual que caracteriza la dinámica demográfica de Villarramiel sigue el mismo curso que en las décadas precedentes, la población continúa disminuyendo, y según el Padrón de 2011 eran 917 los habitantes que residían en el municipio. 
Figura 1. Villarramiel en el contexto regional y provincial.
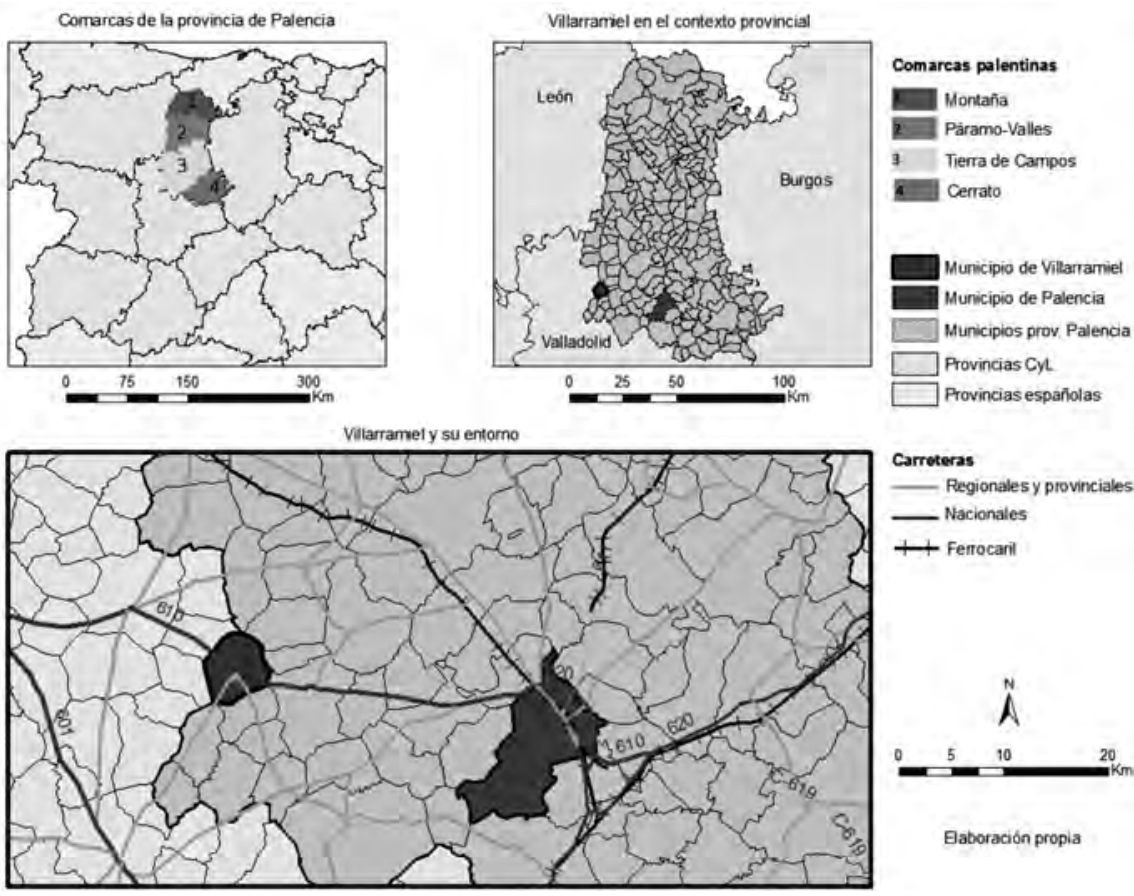

Fuente: Elaboración propia

La pérdida de efectivos demográficos, generalmente jóvenes y económicamente activos, ocasionó un aumento de la edad media de la población muy importante. Fue la gente mayor la que permaneció en Villarramiel frente a los jóvenes que ante la falta de trabajo y oportunidades en su municipio y en los núcleos de alrededor decidieron marchar en busca de fortuna a la capital palentina, a otras ciudades de la región e incluso a otras regiones que buscaban mano de obra para hacer frente al fuerte desarrollo industrial que tuvo lugar entre 1960 y 1970, y sobre todo tras la declaración de Burgos y Valladolid como Polos de Promoción Industrial y Polo de Desarrollo Industrial respectivamente (Pascual Ruiz-Valdepeñas, 2012). Este proceso de emigración ha dado lugar a un fuerte envejecimiento de la estructura demográfica con un 31,40\% de la población mayor de 64 años frente al 8,36\% que tiene menos de 14. El resultado es una pirámide de población totalmente desequilibrada con un fuerte grado de envejecimiento muy característica del interior de Castilla y León.

Como ya se ha comentado, la actividad industrial en Villarramiel ha tenido un peso muy importante en la economía del municipio. A pesar del ocaso sufrido en las últimas décadas sigue constituyendo uno de los sectores más represen- 
tativos en la economía local, y la desaparición de un número muy importante de establecimientos productores de cecina no ha eliminado el interés por la elaboración de este producto. La cecina de caballo de Villarramiel ha pasado de ser un producto destinado a la población más pobre, cuyo objetivo era mitigar el hambre, a convertirse en un producto de calidad reconocido por los consumidores al ser la única cecina elaborada en el territorio nacional con carne de caballo y con una tradición histórica que se remonta al siglo XVII.

\section{EVOLUCIÓN HISTÓRICA DE LA CECINA DE EQUINO DE VILLARRAMIEL}

\subsection{Villa comerciante y trajinera}

La Tierra de Campos se ha caracterizado a lo largo de toda su historia por la importancia económica que poseía la agricultura en la vida de sus habitantes. Sus campos se encontraban cubiertos de cereales, y en menor medida y hasta el siglo XVIII se combinaban con las vides, hoy día prácticamente desaparecidas². La importante actividad cerealística de toda esta comarca presentaba un problema muy importante a la hora de la comercialización del grano como consecuencia de las malas comunicaciones que impedían exportar el cereal. Para solucionar este problema, el Marques de Ensenada, Ministro del rey Fernando VI, propuso la construcción de una serie de caminos y canales para poder comercializar los cereales. Dos años después, el ingeniero Antonio de Ulloa presentó el «Proyecto General de los Canales de Navegación y Riego para los Reinos de Castilla y León». Su construcción comenzó a mediados del siglo XVIII y terminó en el primer tercio del siglo XIX después de una serie de problemas en su financiación. De esta forma se abrió una ruta comercial con el norte de la Península que posibilitaba la venta del grano ${ }^{3}$. Pero dentro de este sector, eminentemente agrario y sin otros recursos para su desarrollo, se localizaba la villa de Villarramiel con un fuerte carácter industrial y comercial, aspectos totalmente diversos del resto de municipios que lo rodeaban ${ }^{4}$.

2 La existencia de los viñedos desde la Edad Media y hasta el siglo XVIII se recoge en el Libro de Alain Huetz de Lemps: Vinos y Viñedos de Castilla y León. Pero a partir del siglo XIX los majuelos fueron desapareciendo, y la presencia de vid crecía por casualidad, no era de buena calidad, y aparecía avergonzada frente a las inmensas extensiones de cereal. Información recogida en El Español, Semanario de los españoles para todos los españoles. Semana del 11-17 Septiembre de 1955, II Época, no 354.

3 La creación del Canal de Castilla constituyó un factor clave para la venta del trigo. Mediante barcas motoras se trasportaba el grano hasta el municipio palentino de Alar del Rey. www. canaldecastilla.org

4 Artículo de El Diario Palentino del sábado 23 de Agosto de 1975 titulado: «Villarramiel: hospitalidad y tesón industrial». En este artículo se hace referencia a la importancia industrial de la villa desde el siglo XVIII. 
Se conocía como un pueblo de trajineros, arrieros, pellejeros, tratantes y comerciantes. Esta intensa actividad industrial estaba apoyada en la compra de equinos procedentes de otros lugares así como los existentes en el propio municipio donde eran sacrificados y despellejados para obtener la piel que posteriormente transformarían en curtidos. Una parte muy importante de la población se dedicaba a esta actividad que constituía un aporte económico de la agricultura ${ }^{5}$.

La actividad industrial y comercial que se realizaba en Villarramiel estaba estrechamente ligada con los animales pero sobre todo con la familia de los equinos: caballos, mulas y asnos. Fueron los Reyes Católicos los que otorgaron un privilegio a la villa para poder dedicarse a maestrías como la del peine, carda, tejidos y sastrerías para todo el reino ${ }^{6}$ aunque sus orígenes se remontan varios siglos atrás. A mitad del siglo XVIII había 105 pelaires, 27 tejedores de estameñas, cordellates, cariseas y otras maniobras de lanas ${ }^{7}$. Pero sin duda alguna la actividad que más destacó y más importancia tuvo en Villarramiel otorgándole mayor prestigio del que ya poseía fue la industria de los curtidos reconocida en toda la comarca y en la provincia de Palencia, y que poco a poco fue consolidando al municipio como un referente en esta actividad en toda España.

En 1724 hay constancia de la existencia de una fábrica de curtidos en la que se fabricaban baldeses y pergaminos. El tamaño de esta empresa era bastante grande para su tiempo, contaba con 19 empleados que trabajan constantemente a lo largo de todo el año y producía 1.508 docenas de baldeses y 500 docenas de pergamino que se vendían en Burgos. A esta fábrica había que añadir la de Francisco López Sánchez, así como otras personas que fueron creando una densa red de instalaciones en torno a este producto trabajando gran cantidad de becerro, cordobán, suelos y otros géneros de curtidos empleando en muchas ocasiones

5 En el Diccionario Geográfico-Estadístico-Histórico de España y sus posesiones de Ultramar de Pascual Madoz. Tomo XVI, Madrid 1850, se relata lo siguiente sobre la economía de Villarramiel: «la principal es la agricultura; luego sigue la arriera, á que se dedican muchos de sus hab.; luego el curtido de pieles y algunos telares de estameñas y telas bastas de lana, y además 4 molinos de linaza:...». Respecto al comercio: «le hace grande en frutos coloniales, bacalao, arroz, aceite y demás producciones naturales de la Península; pero el principal consiste en lanas y cueros y en el transporte de granos y harinas, ocupándose en esto más de 100 carros de camino y muchas caballerías de carga.»

${ }^{6}$ Este privilegio se siguió utilizando a lo largo del siglo XVIII, y gracias a ello se pudo establecer un entramado industrial muy importante en el ámbito de las pieles, tejidos, zapatos, sastrería, etc. Historia de Villarramiel, pág. 251 (Fernández Martín \& Fernández Martín, 1984). La necesidad de animales para la elaboración de estas prendas originaba una excedencia de carne de equino, principalmente, muy abundante que se aprovechaba por las familias más humildes para la elaboración de cecina.

7 Historia de Villarramiel pág. 253(Fernández Martín \& Fernández Martín, 1984). 
entre ocho y diez empleados ${ }^{8}$, y es que, las diversas fuentes documentales como libros, artículos en prensa de la época o archivos $^{9}$ reflejan el esplendor que alcanzaron los curtidos en Villarramiel. La industria de los curtidos se mantuvo a lo largo de los años, y hoy día, aunque con menos esplendor que en sus inicios, se mantiene como una actividad económica representativa del municipio que constituye el principal aporte económico para algunas familias.

Todo parece indicar que esta actividad puede ser la responsable del origen de la elaboración de cecina de equino como se intuye en el Diccionario de Madoz, en diversas fuentes escritas utilizadas, así como en los relatos de las diferentes personas entrevistadas que han ido adquiriendo generación tras generación y que relacionan, sin duda alguna, la industria de la cecina con la de los curtidos y la zapatera, como refleja el dicho popular villarramielense «Al lado de un curtidor, hay un zapatero, y al lado de un zapatero hay un cecinero».

Despellejados los animales para curtir su piel y ante la amenaza de las hambrunas que asolaron estos territorios a lo largo de la historia, se decidió aprovechar los restos de estos animales para elaborar carne curada y adobada a la que denominaron en un principio como Cecina de equino y que podía mantenerse durante todo el año debido a su proceso de elaboración.

\subsection{El desarrollo de la actividad cecinera en Villarramiel}

La importante cabaña de equinos que existía en el municipio, así como aquellos que circundaban esta localidad, contribuyó al auge y expansión de esta industria desde comienzos del siglo $\mathrm{XX}^{10}$. Las primeras referencias escritas que se conservan y que muestran evidencias de la elaboración de esta carne son los partes de sacrificios del Matadero Municipal de Villarramiel del año 1951 con el sacrificio de mulas, caballos y asnos, año en el que se comenzaron sacrificar estos animales

8 Historia de Villarramiel pág. 267 y 268. (Fernández Martín \& Fernández Martín, 1984).

9 Se han encontrado referencias escritas a la existencia de la actividad curtidora en Villarramiel en las fuentes documentales del Archivo de la Real Chancillería de Valladolid haciendo referencia a un pleito civil por parte de «Teresa López Caballero, de Villarramiel (Palencia), Manuel Lozar Prieto, de Villarramiel (Palencia), y Tomás López Alonso, de Villarramiel (Palencia), sobre petición de Teresa López Caballero, mujer de Alonso de Lozar García, preso en Filipinas, para que rinda cuentas de los productos y géneros de curtidos embargados al citado Alonso de Lozar de los que ella era depositaria». Fechado en el año 1827/1829. Signatura PL CIVILES. PÉREZ ALONSO (OLV). Caja 1081.0010.

${ }^{10}$ Respecto a la cecina de equino, Javier Pérez de Andrés en un artículo titulado Cecinas de Castilla y León comentaba lo siguiente "La ciudad de Villarramiel famosa por sus curtidos y fábricas medievales de pergaminos, lanas y textiles alumbraría en los primeros años del siglo veinte un producto singular que respondía a un movimiento constante de transporte de mercancías de tracción animal. (Los villarramielenses recorrían España entera vendiendo y cambiando sus pieles) lo que se presume una cabaña grande de animales de tiro» 
en el matadero ya que anteriormente no estaba permitido y tenía que hacerse en otros lugares. Los primeros partes encontrados proceden de este año, pero según personas relacionadas directamente con el matadero el sacrificio de estos animales se remonta a los años 1944-1945 e incluso antes, ya que antiguamente se realizaban en los corrales y las cuadras de las casas y no se podía dejar constancia en ningún registro al igual que ocurría con las tradicionales matanzas de cerdos.

El mayor esplendor de la cecina de Villarramiel tuvo lugar a mediados del siglo XX, aproximadamente desde 1940 hasta 1975 como consecuencia de las necesidades alimentarias que la población española sufrió después de la Guerra Civil. Para intentar combatir las hambrunas se comenzaron a sacrificar en Villarramiel mulas, caballos y asnos con el objetivo de elaborar cecina y poder obtener alimento. Los animales procedían de personas del propio municipio pero se comenzaron a traer de localidades cercanas haciendo honor al pasado trajinero y comerciante de la villa. De esta forma, el número de cabezas de equino sacrificadas fue aumentando de forma considerable en el municipio, originando una intensa industria cecinera que llegó a contar durante este periodo con casi treinta productores.

Al comienzo de la industria a los animales que se sacrificaban se los denominaba «de desecho» porque eran los equinos más viejos, flacos y no tenían ninguna otra utilidad. La edad media de estos animales solía ser superior a veinte años y en ocasiones contaban con alguna tara física. Los cecineros se encargaban de comprarlos a los agricultores de los municipios de la comarca e incluso de otros núcleos más alejados como en Trigueros del Valle y Cubillas de Santa Marta (actual provincia de Valladolid). En un principio el consumo de carne de caballo, mula o asno no estaba bien visto en la sociedad de la época, por lo que estaba destinado a la población más humilde y con menos recursos económicos que no podía comprar carnes de mayor calidad.

En estos primeros años la legislación sobre el sacrificio de equino era muy escasa y los mataderos no estaban acondicionados para ello. Los controles sanitarios por parte de los inspectores eran inexistentes, cosa que no ocurría en otros países europeos como en Francia donde la carne de equino estaba mejor valorada. Estas carencias en los equipamientos del matadero dieron lugar a que muchos de los sacrificios se realizaran en las propias casas de los productores o incluso en el campo ${ }^{11}$. En este último lugar se depositaban los desperdicios de

${ }^{11}$ En las diferentes entrevistas mantenidas con los principales agentes implicados en el tema, todos ellos han recalcado la clandestinidad a la hora de sacrificar a los equinos debido a la falta de infraestructuras para poder hacerlo en el matadero. Todos ellos coinciden en que en estos primeros años de industria cecinera gran parte de los animales se sacrificaban en las propias casas y en el campo. 
los animales que no eran útiles para la elaboración de cecina. Podían permanecer días e incluso meses hasta que poco a poco se iban transformando en abono. Esta estampa permaneció en los campos de Villarramiel hasta que se decidió vender los restos de los animales sacrificados a una fábrica en el municipio vallisoletano de Cabezón de Pisuerga. En ella se transformaban en cola para la industria y grasas que a su vez estaba destinada a otras fábricas para la elaboración de jabón.

Otra de las actividades que se comenzó a desarrollar vinculada a la cecina fue la elaboración de embutidos. Para ello se utilizaban los restos de las piezas de equino inservibles para la carne curada y de esta forma las personas más humildes del municipio podían satisfacer una parte de sus necesidades alimentarias y económicas. La cecina y el resto de embutidos tenían como mercado la ciudad de Valladolid pero sobre todo los barrios más pobres de Palencia, como los del entorno del Cristo del Otero. Su transporte se realizaba a través del Tren del Secundario que unía diariamente Medina de Rioseco con Palencia. La entrada de estos productos no estaba permitida en la ciudad por lo que todos los trenes que llegaban a la estación de Palencia tenían que pasar un control de seguridad. Al llegar a las inmediaciones de la capital el tren aminoraba su velocidad y se tiraban desde los vagones los sacos con la cecina y los embutidos de equino gracias a la complicidad que existía entre los maquinistas y los productores de Villarramiel. Una vez arrojados del tren, un grupo de personas se encargaba de recogerlos y distribuirlos por los barrios de la ciudad entre los grupos sociales más modestos y con menos recursos. Esta actividad, aunque ilegal en su momento, ayudó a mitigar las hambrunas de los más pobres.

El crecimiento de la actividad cecinera dio lugar a un incremento en el número de sacrificios de ganado equino, por lo que a partir de 1950 se autorizó a sacrificar este ganado en el matadero municipal de Villarramiel habilitando una nave específica para estos animales. El veterinario del pueblo era el encargado de supervisar la inspección de los animales que se sacrificaban, así como posteriormente llevar a cabo los controles sanitarios de la carne de cecina que se elaboraba. Es a partir de este momento cuando se empieza a tener constancia de esta actividad y la información sobre la elaboración de cecina en Villarramiel comienza a ser cada vez más numerosa.

Los primeros partes de sacrificio que se conservan en el Archivo Municipal del Ayuntamiento de Villarramiel sobre el sacrificio de equinos datan de 1951. En este mismo año se comenzaron a matar asnos, caballos y mulas en cantidades pequeñas, ya que la mayor parte se seguía haciendo en las casas particulares. Pero con el paso de los años los controles sanitarios aumentaron y obligaron a 
todos los cecineros a acudir al matadero a sacrificar sus reses además de pagar los impuestos pertinentes al ayuntamiento ${ }^{12}$.

La habilitación en el matadero de un espacio para sacrificar equinos trajo consigo la solicitud y concesión de las primeras licencias de apertura de establecimientos de elaboración de cecina, concediéndose la primera de ellas el 31 de agosto de 1954 a un vecino de la localidad ${ }^{13}$.

El incremento de esta actividad provocó un aumento del número de reses necesarias para la elaboración de la carne. Además de abastecerse de las existentes en el propio municipio, de los pueblos colindantes y de la feria que se celebraba en marzo en Villarramiel, se empezó a acudir a los diferentes mercados y ferias de equino de la región y del resto de España para comprar el ganado. Las más importantes que se celebraban en la región eran en Almazán, en la provincia de Soria, Toro en Zamora, Valderas y Mansillas de las Mulas en la provincia de León, en la propia capital leonesa en la festividad de San Andrés y en Turégano en Segovia, así como algunas localidades del entorno de Villarramiel. En este caso el traslado de los animales se hacía a pie, en tren y en camiones de ganado.

Además de todos estos lugares que contaban con un mercado específico de esta carne acudían a otros municipios en busca de las piezas de desecho que los agricultores tenían para sus labores agrarias y que por la edad del animal no podía cumplir con sus obligaciones en el campo, por lo que eran vendidos para carne. Fuera del territorio regional, los cecineros de Villarramiel acudían a otras grandes ferias que se celebraban principalmente en Aragón, pero sobre todo en las localidades extremeñas de Mérida, Zafra y Trujillo, así como en Oropesa, en la provincia de Toledo, donde compraban cientos de equinos entre los diferentes cecineros.

La llegada de este ganado a Villarramiel era lenta, difícil y costosa. El ganado procedente de las localidades de la provincia de León se trasladaba en vagones de tren que llegaban hasta el municipio. En este caso el transporte no presentaba mayores dificultades pero este se complicaba cuando el ganado procedía de las ferias de otras regiones. En estos casos se trasladaba en vagones de tren hasta la estación de Dueñas (Palencia). Debido a la gran cantidad de ganado que se

${ }^{12}$ Partes de sacrificio de ganado equino en el matadero municipal de Villarramiel. 1951 y 1952. En estos documentos, específicos para este tipo de ganado equino, comienzan a figurar los primeros sacrificios de mulas, caballos y asnos. Archivo Municipal del Ayuntamiento de Villarramiel.

${ }^{13}$ Este documento es uno de las primeras actas de comprobación que se han encontrado en los Archivos municipales del Ayuntamiento de Villarramiel. El informe refleja la concesión para poner en marcha una instalación destinada a cecinado de carne de équido a cargo de Federico Palencia Rodríguez en la Calle Lagunillas en Villarramiel en el año 1954. Documento obtenido en el Archivo Municipal/Sección Matadero Municipal del Ayuntamiento de Villarramiel. 
adquiría se fletaban trenes completos de mulas y asnos principalmente, y en menor medida de caballos. Una vez en Dueñas, el resto del camino, unos $42 \mathrm{Km}$, se hacía a pie hasta Villarramiel por la carretera de Ampudia. En ocasiones los equinos más viejos no conseguían llegar hasta el pueblo y tenían que ser sacrificados durante el viaje, abandonando sus restos en las cunetas de las tierras que encontraban a su paso. Una vez en Villarramiel se hacía un recuento del ganado por parte de la policía municipal con el fin de aplicar a cada productor de cecina una tasa que había establecido el Ayuntamiento de la que obtenía cuantiosos beneficios.

Desde este momento se comenzó a regularizar esta industria que hasta la fecha apenas tenía controles por parte de las autoridades municipales. Se comenzó a sacrificar a los animales en el matadero, se concedieron licencias de establecimientos y se generó un tejido económico más allá de la elaboración de cecina con la aparición de otras actividades económicas derivadas de esta producción.

\subsection{Legalización de la actividad y el desarrollo de industrias auxiliares}

La expansión de la industria cecinera contribuyó a la aparición de otras actividades fabriles en el municipio que permitieron aprovechar todas las partes de los equinos y evitar arrojar a las tierras sus desperdicios. De esta forma surgieron las fábricas de molturación de piensos Rebolleda, la fábrica de tripas del Señor Benis, pero sobre todo la fábrica de harinas denominada Concentrados Proteicos Marisa. Esta última fue fundada el 31 de diciembre de 1957 por Julián Prieto Paramio y David Pérez, siendo la fábrica con mayor producción y empleo de las tres existentes. Se encontraba en la Calle Lagunillas, en el centro de Villarramiel, pero debido a los olores que desprendía se vieron obligados a trasladarse a unos tres kilómetros del núcleo urbano, en las inmediaciones del Canal de Castilla, muy cerca del término municipal de Castromocho, en la carretera que une el pueblo con Palencia. Llegó a tener unos 10 empleados y en ocasiones se encontraba en funcionamiento las 24 horas del día dependiendo de la actividad que hubiese en el matadero municipal. Se aprovechaban los residuos de los equinos como los huesos y la sangre para realizar piensos compuestos que enviaban a empresas de toda España, pero sobre todo de Aragón y para la empresa sevillana ISENASA.

La fábrica cerró sus puertas en el año 1974 coincidiendo con la decadencia de la industria cecinera y el éxodo rural que afectó duramente al municipio ${ }^{14}$. Finalmente, la piel se aprovechaba en el resto de fábricas para la elaboración de curtidos. De esta forma y hasta 1975 la actividad industrial de Villarramiel cono-

${ }^{14}$ Villarramiel se vio seriamente afectado y su población disminuyó en casi 1.500 personas entre 1950 y 1981. 
ció una expansión única en su historia convirtiéndolo en uno de los municipios más ricos y dinámicos de la Tierra de Campos palentina ${ }^{15}$.

La llegada de abundante ganado y el auge de la actividad animaron a muchas personas del pueblo a dedicarse a la elaboración de cecina de forma industrial solicitando nuevas licencias para la apertura de establecimientos elaboradores de este producto. De esta forma se comenzaron a formalizar las instalaciones y se incrementaron las exigencias y los controles por parte de las autoridades sanitarias lo que obligó a los cecineros a acondicionar sus antiguos locales, generalmente situados en las cuadras o en alguna habitación de sus viviendas, en espacios aptos para sacrificar animales.

Para obtener estos permisos tenían que solicitar al Ministerio de Agricultura, a través de la Jefatura Agronómica de Palencia, unas licencias que les permitiesen abrir sus establecimientos. En estas actas el personal cualificado de la Jefatura Provincial era el encargado de conceder las licencias tras la realización de los informes correspondientes siempre que se cumpliese el Decreto ley de 1 de Mayo de 1952 y la Orden Ministerial de Agricultura de 15 de Julio del mismo año. La legislación sobre esta materia se fue incrementando con el tiempo y años más tarde se publicó en el Boletín Oficial de la provincia de Palencia una Orden del Ministerio de la Gobernación, de 15 de Marzo de 1963, sobre las aplicaciones del Reglamento de Actividades molestas, insalubres, etc. En esta Orden se recogen un total de 13 puntos que hacen referencia a este tipo de instalaciones apareciendo la elaboración de cecina de equino de Villarramiel en el cuarto puesto.

Los requisitos para obtener alguna de estas licencias cada vez eran mayores, pero a pesar de todo, entre mediados de los cincuenta y finales de los sesenta se fueron incrementando el número de productores cecineros que querían legalizar su situación y se comenzaron a solicitar más licencias. Una de ellas fue la del productor Julio Caballero Guerra, al cual le fue concedida la autorización para elaboración de cecina de carne de équido el 30 de marzo de $1968^{16}$.

${ }^{15}$ El Diario español en su número 354 de septiembre de 1955 refleja la importante industria del municipio, que haciendo referencia a los olores de la villa se menciona la extrañeza de los visitantes por el mal olor del pueblo debido a las fábricas de curtidos, a los que los villarramelienseses les contestan diciendo que $<<$ Aquí huele a pesetas $>>$. Blanca Espinar corrobora en su artículo estos hechos y lo justifica diciendo: «Sí, aquí huele a pesetas no hay que dudarlo, porque la villa vive en la abundancia que le proporciona su productiva industria; ...»

${ }^{16}$ Informe de la Subdirección General de «Industrias Agrarias» del Ministerio de Agricultura en la que se otorga a D. Julio Caballero Guerra la autorización para la instalación de una industria de elaboración de cecina de carne de équido el 30 de Marzo de 1968. El lugar de la instalación es el municipio de Villarramiel (Palencia), y en ella se detallan las condiciones a las que se encuentra sujeta esta fábrica, así como su inscripción en el registro especial correspondiente de la Subdirección General correspondiente. Documento obtenido en el Archivo Municipal/Sección Matadero Municipal del Ayuntamiento de Villarramiel. 
En total llegaron a ejercer de forma legal esta actividad 23 productores de cecina de equino, según refleja un consorcio por parte del Ayuntamiento de Villarramiel y los productores de cecina de 1968. En este documento se obligaba a los cecineros a matar las reses en el matadero municipal, el número de reses que podían sacrificar al año cada uno, así como los impuestos correspondientes por esta actividad que debían pagar (45 ptas en 1968 por cada animal sacrificado en el matadero). El número medio de animales sacrificados por cada productor rondaba entre las 110 y 130 reses, pero algunos de ellos como Eutiquio Roldán Rojo, llegó a sacrificar al año 400, frente a otros que tan sólo sacrificaron 10 o 20. El consorcio, en 1968-1969, otorgó licencia para sacrificar un total de 2.480 animales equinos de los que el Ayuntamiento obtuvo unos ingresos de 111.600 ptas. por los servicios prestados $^{17}$.

En los años posteriores, $1972-1973^{18}$ y $1973-1974^{19}$, se redujeron a 20 los productores de cecina. El procedimiento para el sacrificio de reses era idéntico al explicado anteriormente y el impuesto que se pagaba al Ayuntamiento por cada res sacrificada seguía siendo de 45 pesetas. El cómputo global que cada productor debía pagar al Ayuntamiento se calculaba para todo el año pero se daba la opción de realizar dicho pago por cuatrimestres. Entre el 1 de septiembre de 1972 y el 31 de agosto de 1973 se sacrificaron un total de 2.613 equinos, y muchos productores incrementaron el número de reses al año superando las 150 e incluso las 200, siendo, al igual que el caso anterior, Eutiquio Roldán Rojo la persona que más equino sacrificaba pero menos que en 1968, con un total de 280 reses.

${ }^{17}$ Consorcio establecido entre el Ayuntamiento de Villarramiel y los productores de cecina para establecer el número de reses que podía sacrificar cada uno, y el importe que debía pagar al Ayuntamiento por este sacrificio. En este documento se detalla una lista con los 23 productores de cecina que había en 1968, y el número de reses que sacrifica cada uno. Documento obtenido en el Archivo Municipal/Sección Matadero Municipal del Ayuntamiento de Villarramiel.

${ }^{18}$ Relación nominal de las reses equinas adjudicadas a cada propietario para el ejercicio de 1972-1973, así como la cantidad a pagar al Ayuntamiento por los servicios de matadero. Documento obtenido en el Archivo Municipal/Sección Matadero Municipal del Ayuntamiento de Villarramiel.

${ }^{19}$ Concierto para el ejercicio 1973-1974 en el que se especifica las reses a sacrificar por cada productor de cecina, así como la cantidad a pagar al Ayuntamiento de Villarramiel por los servicios de matadero. En este periodo, se produce un descenso en el número de reses sacrificadas, coincidiendo con el periodo de decadencia de esta industria ayudada por el éxodo rural tan intenso que azotó a los municipios del interior de Castilla y León, pero con especial incidencia en los núcleos de la Tierra de Campos vallisoletana y palentina. Desde estos años, el número de reses sacrificadas comenzó a disminuir, a la vez que fueron desapareciendo las diferentes industrias cecineras. 
Además de los sacrificios que se realizaban en el matadero municipal hay que sumar aquellos que se llevaban a cabo de forma fraudulenta en las propias casas y que llegaron a suponer hasta un $25 \%$ de los que se realizaban en el propio matadero. Este dato se ha puesto de manifiesto en todas las reuniones celebradas con los diferentes agentes implicados y coinciden en la importancia que tenían estos sacrificios a pesar de las diferentes ordenanzas del ayuntamiento que obligaban a los productores a sacrificar las reses en el matadero como reflejan diversos partes del Ayuntamiento de Villarramiel ${ }^{20}$.

El principal tipo de animal que se sacrificaba era el equino (ver figura 2). En pocos años el matadero se había transformado por completo y lejos quedaban los tiempos en los que no estaba permitido matar animales de esta raza y solo se permitía el sacrificio de vacas, cerdas, ovejas, cabras, etc. Este hecho fue un aliciente muy importante para mantenerlo abierto tras la oleada de cierres que se produjeron en la década de los ochenta al no cumplir las condiciones de salubridad requeridas por la Ley. La Consejería de Agricultura, Ganadería y Montes subvencionó una parte muy importante de las obras de remodelación que se produjeron en el mismo con una inversión superior a los 2,5 millones de pesetas (unos 15.000 Euros). De esta forma Villarramiel se convirtió en el matadero comarcal de los 21 municipios que componían esta comarca de Tierra de Campos palentina ${ }^{21}$.

La industria cecinera comenzó a decaer a partir de finales de la década de 1970 y comienzos de 1980, reduciendo drásticamente el número de cabezas sacrificadas y los establecimientos elaboradores ${ }^{22}$. Los motivos de este descenso se encuentran en el aumento del consumo de otro tipo de carnes como las aves y el cerdo, así como el descenso de la cabaña de equinos existentes.

En la evolución del número de sacrificios de equinos se diferencian dos periodos de fuerte crecimiento, dos de estancamiento y uno de pequeña recuperación. El máximo crecimiento tiene lugar a mediados de los años cincuenta coincidiendo con la expansión de esta industria y la apertura de los diferentes

${ }^{20}$ Las Ordenanzas del Ayuntamiento de Villarramiel obligan a cumplir la legislación vigente en lo concerniente al sacrificio de reses equinas a todos los productores de cecina. Se deberá realizar los días laborables en el horario establecido. 14 de septiembre de 1973. Documento obtenido en el Archivo Municipal/Sección Matadero Municipal del Ayuntamiento de Villarramiel.

${ }^{21}$ Noticia recogida en El Norte de Castilla el 24 de Diciembre de 1984 titulada: «El matadero de Villarramiel será comarcal desde enero» escrita por Celsa Pardo. Las mejoras que se llevaron para acondicionar el Matadero municipal fueron sufragadas por la Administración pública, otorgando una categoría superior a los mataderos municipales al convertirse en comarcal. Las mejoras consistían en un alicatado de las paredes azulejándolas hasta 2,5 metros de altura y pintando el resto de la pared, acondicionamiento de los desagües de aguas residuales, instalación de una cámara de oreo, construcción de cuadras y dotación de transporte isotermo.

${ }^{22}$ Historia de Villarramiel pág. 294. 
establecimientos. El otro máximo ocurrió a mediados de los setenta debido al proceso de sustitución de los animales de tiro por la maquinaria agrícola, el cual fue muy intenso, eliminando prácticamente toda la cabaña de este tipo de reses en los campos de Villarramiel y de los municipios colindantes. Entre estos dos periodos se produjeron fluctuaciones en el número de sacrificios coincidiendo con el cierre de algunas empresas y el fuerte peso que tuvo el éxodo rural. Pero la caída más fuerte ocurrió a partir de mediados de la década de 1970 coincidiendo con el desplome de esta actividad. A finales de la década de 1980 se volvió a incrementar el número de sacrificios ocasionado por un cambio en su industria orientándose hacia la producción de cecina de mayor calidad y solamente de caballo (figura 3).

Figura 2 Ganado sacrificado en el matadero de Villarramiel entre 1975-1983.

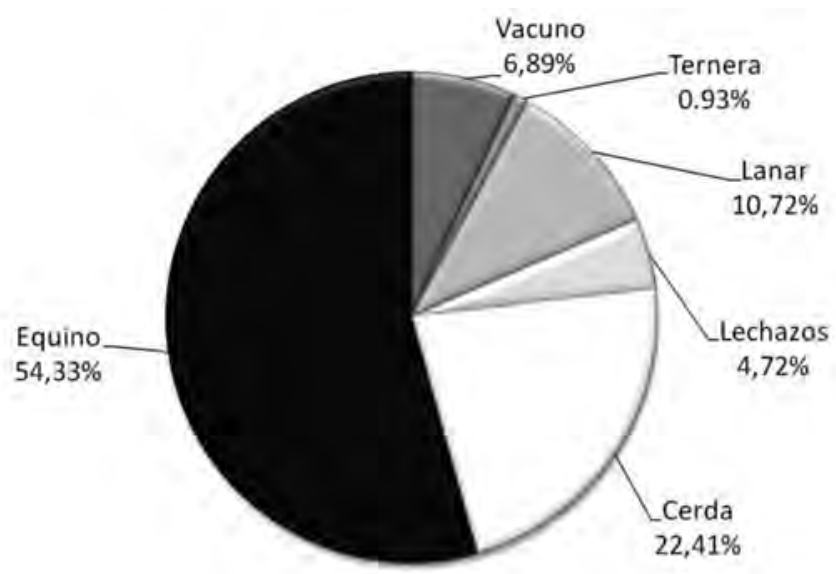

Fuente: Archivo Municipal Ayuntamiento de Villarramiel. Elaboración propia

A mediados del siglo XX las mulas y los asnos representaban más del 85\% y en algunos años, como en 1957, hasta el 98\% de los equinos sacrificados. Con el paso de los años los caballos fueron adquiriendo mayor notoriedad y llegaron a representar el 24,53\% en 1968, 25,56\% en 1969 y el 26,75\% en 1970. La presencia de asnos y mulas en las tareas del campo era muy importante y por esto tenían mayor peso que los caballos. Estas cifras se comenzaron a invertir a finales de la década de los ochenta cuando el animal que más se mataba era el caballo, alcanzando cifras del 54\% en 1990, 84,93\% en 1991, y 85,31\% en 1992.

La industria cecinera se estaba orientado a la producción de carne de mayor calidad dedicándose exclusivamente a la elaboración de cecina de caballo dejando atrás el resto de equino. A partir de comienzos de la década de 1990 se realizó una campaña muy importante para dar a conocer la cecina no solo en 
la provincia de Palencia sino en toda la región de Castilla y León, en el resto de España e incluso en diferentes países europeos, americanos y asiáticos.

Figura 3. Evolución del número de equinos sacrificados en el matadero de Villarramiel 1951-1992.

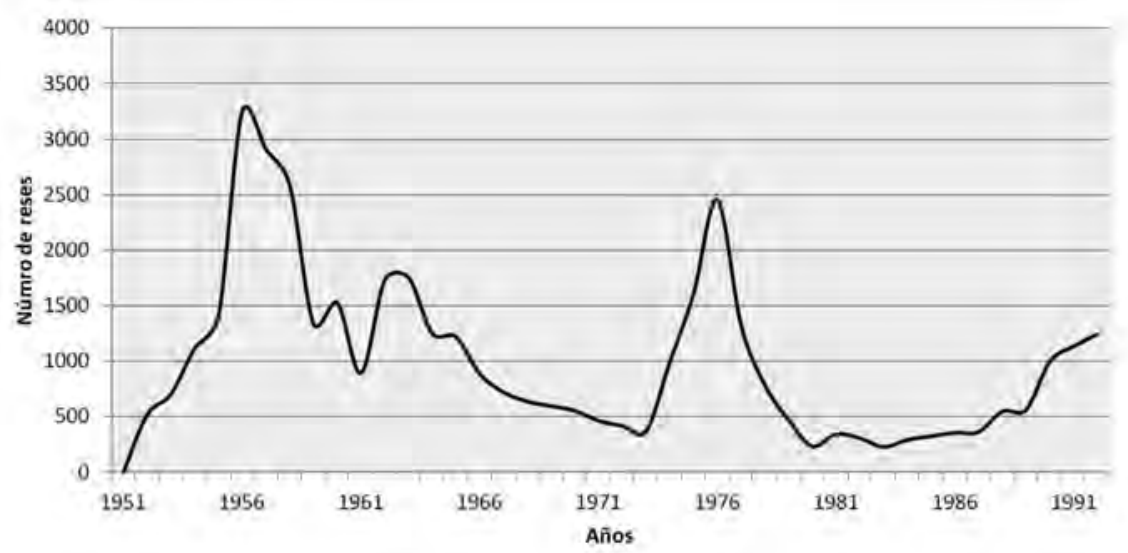

Fuente: Archivo Municipal Ayuntamiento de Villarramiel. Elaboración propia

En este periodo los productores cecineros se habían reducido a cuatro, y posteriormente, a comienzos del siglo XXI, otro productor cerró sus puertas tras jubilarse y no encontrar relevo generacional por parte de sus hijos reduciéndose finalmente a tres el número de productores en la localidad, cifra que se conserva en la actualidad. Las tres industrias cecineras han pasado de padres a hijos, lo que ha permitido continuar con la actividad de forma tradicional y han mostrado mayor interés por la expansión del mercado a través de la inclusión en diversas asociaciones de calidad local, provincial y regional con el objetivo de promocionar un producto único en España. Esto unido a los nuevos medios que ofrecen los sistemas web, la prensa, las ferias, etc. han contribuido a la difusión y conocimiento de este producto.

\section{EL NUEVO ENFOQUE DEL PRODUCTO: LA APUESTA POR LA CALIDAD}

Los últimos años de la década de los 80 y los primeros de los 90 constituyeron un tiempo de restructuración de la industria cecinera enfocándose principalmente a la producción de cecina de caballo, y a su incremento entre los consumidores a través de la promoción y difusión en los medios de comunicación, ferias gastronómicas, etc.

A partir de entonces el acceso a los mass media ha ido dando cada vez más información sobre este producto con nuevas referencias en libros y guías gastronómicas, 
en artículos de prensa, asistencia a salones agroalimentarios nacionales e internacionales, la creación de páginas web, etc. así como la adscripción y creación de diferentes asociaciones cuyo reto actual es obtener la Marca de Garantía para este producto.

La década de los noventa se encaminó hacia la consolidación de la cecina de caballo de Villarramiel como un producto único en su especie. Esta tarea se presentaba difícil tras la decadencia de la industria cecinera en el municipio y la disminución de los productores. El principal reto que se planteó en los noventa fue la creación de un matadero específico de equino que cumpliese las nuevas condiciones impuestas por la Comunidad Europea que obligaba a sacrificar los animales de forma separada. A pesar del descenso del número de reses equinas la adaptación del matadero era imprescindible para poder sacrificar a los animales y mantener esta industria en Villarramiel ${ }^{23}$.

El proyecto de matadero para equinos suponía un coste de unos 100 millones de pesetas (600.000 Euros), lo cual repartido entre los cuatro productores de cecina que permanecían en el municipio suponía un aporte de 25 millones de pesetas (150.000 Euros) cada uno, cifras demasiado elevadas para unos empresarios pequeños ${ }^{24}$. Para conseguir la financiación exterior y poder realizar el matadero se constituyó la denominada Asociación de Productores de Cecina de Equino de Villarramiel el 24 de mayo de 1993. Estaba formada por los cuatro productores de cecina que había en el municipio, ostentando cada uno de ellos los cargos más representativos, y cinco vocales. De esta forma Julio Caballero Guerra fue nombrado presidente de la Asociación, Emeterio Sánchez Bello vicepresidente, Pablo Fernández Martín secretario y Pedro Rojo Rodríguez tesorero. Aparte de los socios productores de cecina podían formar parte de la Asociación todas las personas e instituciones que compartiesen el mismo objetivo que los productores 25 y 26 .

${ }^{23}$ El Diario Palentino, 20 de agosto de 1993. Fiestas de San Bartolo. Entrevista a Pablo Fernández, secretario de la Asociación de Cecineros de Villarramiel, realizada por Jorge Cancho. En esta entrevista se analizan las perspectivas del futuro de la cecina de Villarramiel que pasan por la construcción de un matadero exclusivo para el sacrificio de equinos.

${ }^{24}$ El Norte de Castilla 26 de marzo de 1993. Se relata la necesidad de un nuevo matadero y el coste que supondría para cada industrial cecinero.

25 El Norte de Castilla, sección Palencia. Jueves 27 de mayo de 1993. Noticia titulada«Cuatro industriales fundan una asociación para promocionar la cecina a nivel nacional» escrita por Celsa Pardo. La promoción de la cecina en Ferias y libros especializados fue un gran éxito como se explicará más adelante. Todo lo contrario a la idea de conseguir la Denominación de Origen, que nunca se obtuvo debido a diferentes factores, entre ellos, la escasa productividad de los diferentes productores y lo costoso que sería el mantenimiento del Consejo Regulador para los cuatro pequeños productores.

${ }^{26}$ El día de Palencia, 29 de mayo de 1993. Noticia titulada Constituida la «Asociación de Productores de Cecina de Equino de Villarramiel» escrita por Santiago Novoa Montes, Animador sociocultural de Villarramiel. 
A pesar de las iniciativas que se llevaron a cabo, el matadero de equino de Villarramiel nunca llegó a construirse, situación que se agravó cuando en 1995 se cerró el matadero municipal. De esta forma, en un primer momento, los cecineros se vieron obligados a sacrificar sus caballos en el de Palencia y posteriormente en Medina de Rioseco, cerrando de esta forma una parte de este proceso que ha tenido un fuerte calado en el tejido económico y social de Villarramiel.

A día de hoy, la calidad es una de las mayores apuestas por parte de los Organismos Oficiales con la creación de diversas Asociaciones y las diferentes figuras de calidad han ayudado a la comercialización de los productos de la Tierra de Castilla y León.

La cecina de Villarramiel, además de poseer una Asociación de Productores propia, se encuentra dentro de diferentes Asociaciones como Alimentos de Palencia, Artesanos y Alimentos de Castilla y León, y más recientemente los productores se han incorporado al sello de calidad Tierra de Sabor.

Estas cuatro Asociaciones contribuyen a la promoción y difusión de este producto por todo el territorio regional y su objetivo es distinguirlos frente al resto de productos agroalimentarios. A través de estas asociaciones se consigue una promoción eficaz del producto con su presencia en medios de comunicación, ferias, publicaciones, etc.

\section{EVOLUCIÓN RECIENTE DE LA INDUSTRIA DE CECINA DE CABALLO}

La actividad cecinera de Villarramiel ha experimentado una serie de transformaciones desde sus orígenes hasta la actualidad. Hoy día permanecen tan sólo tres productores frente a los 23 que existieron legalmente a mediados del siglo XX. Sus instalaciones se han ido adaptando a los tiempos y han experimentado una serie de cambios con el objetivo de satisfacer la demanda de su mercado. Los tres productores existentes en la actualidad han heredado de sus progenitores el arte en la elaboración de este producto que tanto renombre ha dado al municipio.

La producción de cecina se ha mantenido más o menos estable en los últimos seis años entre los 56.000-61.000 Kg (figura 4) a pesar de las dificultades económicas ocasionadas por la actual crisis, experimentando un ligero descenso en su producción en alguno de los productores. Esta producción se divide entre las tres empresas que continúan en el negocio: Cecinas Hermanos Caballero Rojo, Cecinas Fernández y Cecinas Emeterio Sánchez. 
Figura 4. Evolución de la producción de Cecina de caballo de Villarramiel 2005-2010.

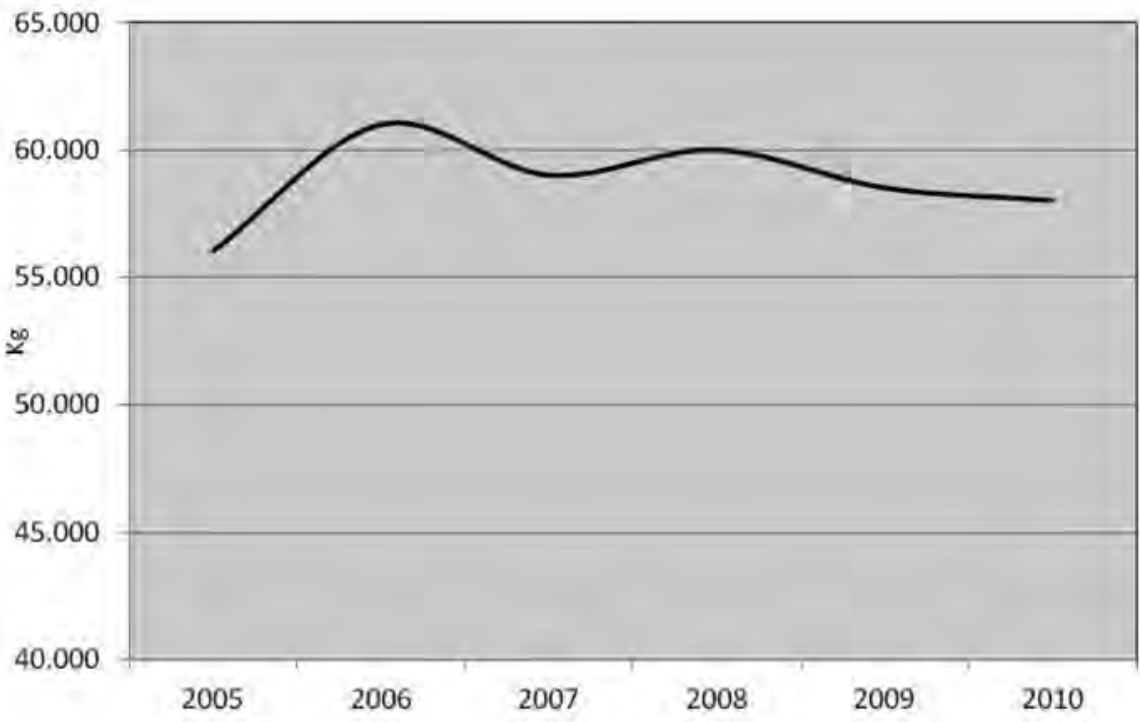

Fuente: Encuestas a los empresarios de Cecina de Villarramiel. Elaboración propia

Los Hermanos Caballero Rojo toman el relevo de esta industria en 1995 a su padre Julio Caballero Guerra que la fundó en los años sesenta. Es la fábrica con mayor producción de las tres existentes con un total de $27.500 \mathrm{Kg}$ de cecina de caballo (año 2010). Desde finales de los noventa y comienzos de la década del 2000 la producción se fue incrementando como consecuencia del cierre de una cuarta industria que existía en el municipio. El propietario era Pedro Rojo, familiar directo de Hermanos Caballero Rojo, por lo que gran parte de la cartera de clientes fueron a parar a su negocio. Además de la cecina han ido diversificando su producción con la elaboración de otros productos como salchichón y chorizo de caballo procedente la materia prima de Galicia y Salamanca, sacrificando una media al año de 280 en el matadero de Medina de Rioseco.

Los ingresos que se han obtenido por la venta de cecina en los últimos años han experimentado un crecimiento positivo al pasar de los 250.000 Euros de 2005 a los 357.000 de 2010, ocasionado por su expansión en el mercado y por su encarecimiento. Su ámbito de ventas es principalmente regional repartido entre el mercado local en un 15\%, el provincial con un $25 \%$ y el $40 \%$ en las demás provincias de la región. El restante 20\% se debe al comercio nacional distribuido principalmente entre Aragón, Andalucía, Madrid y el norte peninsular. 
Los tres productores que permanecen en la actualidad en Villarramiel han tomado el relevo en esta actividad de mano de sus padres, y estos a su vez de sus abuelos, lo que demuestra el carácter artesanal de la actividad. Presentan unas características similares en su forma de elaboración, en su producción, en sus mercados y en la procedencia de la materia prima. El mayor productor es Hermanos Caballero Rojo con un 47,42\% de la cantidad total de cecina elaborada en 2010, frente al 31,03\% de Cecinas Fernández, y el 21,55\% de Emeterio Sánchez.

En el conjunto global la producción total de cecina se ha mantenido más o menos estable en los últimos seis años. Se ha pasado de producir $56.000 \mathrm{Kg}$ en $2005 \mathrm{a}$ $58.000 \mathrm{Kg}$ en 2010. El mayor crecimiento ha sido el experimentado por la empresa de los Hermanos Rojo que ha incrementado su producción entre 2005-2010 en $6.500 \mathrm{Kg}$ de cecina, frente a la pérdida de $2.500 \mathrm{Kg}$ de Emeterio Sánchez. Respecto a Cecinas Fernández la tendencia en su producción se ha caracterizado por un fuerte incremento entre 2005-2007 de $5.000 \mathrm{Kg}$, alcanzando los $25.000 \mathrm{Kg}$ para luego disminuir hasta los $18.000 \mathrm{Kg}$ en 2010 a causa de la actual coyuntura económica.

Aparte de la cecina, la producción de embutidos ha supuesto un crecimiento muy importante en esta industria chacinera para algunas de las empresas. Los Hermanos Caballero Rojo vuelven a situarse a la cabeza en la producción de embutido de caballo con un crecimiento de más de $10.000 \mathrm{Kg}$ de salchichón y chorizo en este periodo de estudio con casi el 90\% de la producción. Este crecimiento del embutido ha restado importancia al conjunto global de producción de cecina que en 2005 representaba el 88,46\% de la producción total de esta industria frente al 7,98\% del embutido de caballo y el 3,55\% de cerdo, mientras que en el año 2010 la cecina representaba el 74,85\% frente al 22,25\% de los embutidos de caballo y el 2,90\% de los de cerdo.

\section{CONCLUSIÓN}

Las figuras de calidad en Castilla y León constituyen un elemento dinamizador del territorio y diferenciador de los productos agroalimentarios que posee un territorio. Su reconocimiento puede constituir un activo económico y social de gran calado ayudándole a diversificar su propia economía.

En estas páginas se ha presentado el caso de un producto muy característico de un sector de la Tierra de Campos que lucha por conseguir la Marca de Garantía. La elaboración de cecina de caballo en Villarramiel ha constituido siempre una actividad económica con una huella importante en el municipio. A lo largo de la historia han sido muchas las personas que han establecido algún vínculo económico y social con esta profesión por lo que presenta una fuerte identidad entre la población y prácticamente todos los habitantes han tenido alguna relación directa o indirecta con este producto. 
En los años de la posguerra civil española constituyó un alimento básico en la dieta de la población más desfavorecida. Fue a mediados del siglo XX cuando se comenzó a regularizar la situación y se otorgaron las primeras licencias oficiales para la elaboración de este producto aunque la producción de cecina se remonta a principios de siglo. En total se concedieron más de veinte permisos para la instalación de espacios destinados a la elaboración de cecina de equino. Desde entonces se ha ido consolidando en Villarramiel una industria única en todo el territorio nacional basada en la salazón y adobo de carne de equino y desde finales de los ochenta solo de carne de caballo.

Esta investigación tenía como objetivo reconstruir la historia de este producto y su valor económico con el fin de demostrar la impronta que ha tenido en el territorio desde sus orígenes hasta la actualidad. Esta industria ha pasado de ser el soporte principal de más de veinte familias de forma directa entre 1950-1970 a ocho familias en 2012. A pesar de todo esta industria agroalimentaria constituye un elemento vertebrador del tejido económico y social de Villarramiel de Campos que consigue facturar anualmente unos 700.000 Euros, cifra no muy elevada pero que contribuye a la diversificación económica, basada en la agricultura, de este municipio y de los colindantes.

\section{AGRADECIMIENTOS}

Me gustaría terminar este artículo agradeciendo a María del Henar Pascual RuizValdepeñas, profesora titular del Departamento de Geografía de la Universidad de Valladolid, la confianza que ha depositado en mí, y a Mónica Marina Ortega, Licenciada en Historia y Arqueóloga, por su ayuda en el archivo de Villarramiel.

\section{BIBLIOGRAFÍA}

Alonso Santos, J. L. et al. (2003): «Los espacios vitivinícolas en Castilla y León: la evolución hacia un sistema productivo de calidad», Boletín de la A.G.E., n³5, pp.101-122.

Aparicio, J. et al. (2008): «La Ribera del Duero, geografía de un medio innovador en torno a la viticultura», Scripta Nova, 277, revista digital sin páginas.

Caballero Fernández-Rufete, P. et al. (2012): «La evolución demográfica de Castilla y León: una trayectoria que refleja los rasgos y manifiesta las contradicciones del modelo español» en DELGADO URRECHO, J. (ed.), Población y poblamiento en Castilla y León. Consejo Económico y Social de la Comunidad de Castilla y León. Valladolid, pp. 299-528.

Casanova Todolí, U. (1999): Alimentos de calidad de Castilla y León. Junta de Castilla y León, Colección Mundo Rural. Valladolid, 191 pp. 
De La Calle Robles, L. (2002): «Denominaciones de origen y protección económica», Estudios agrosociales y pesqueros, nº194, pp. 27-48.

Del Pozo Del Blanco, S. (2001): «Cecina de León, uniendo calidad e historia», Gestión de hoteles, n³9, pp. 40-42.

Dirección General De Industrias Agrarias Y Desarrollo Rural (2000): Alimentos de Castilla y León: denominaciones de calidad en Castilla y León, Junta de Castilla y León (Consejería de Agricultura y Ganadería). Valladolid.

Fernández Barcala, M. et al. (2001): «Los indicadores geográficos como garantía de calidad: organización y perspectivas en el sector agroalimentario», Revista asturiana de economía, n²2, pp. 27-46.

Fernández Gil, M. (1983): «Apuntes palentinos. Gastronomía». Usos y costumbres, $\mathrm{n}^{\circ}$ 5. Ed. Caja de Ahorros y Monte de Piedad de Palencia, Obra Cultural.

Fernández Martín, L. y Fernández Martín, P. (1964): Villarramiel de Campos. Nuevos datos para su historia. Escuela gráfica Salesiana. Madrid, 191 pp.

Fernández Martín, L. y Fernández Martín, P. (1984): Historia de Villarramiel. Diputación Provincial de Palencia. Palencia, 383 pp.

FERnÁNDEZ NúÑEz, M. T. (2000): «La industria agroalimentaria en España: características generales y comportamiento empresarial», Boletín económico de IC, Información Comercial Española, n²657, pp.17-27.

Fernández Portela, J. (2012): «La industria agroalimentaria como elemento vertebrador del espacio rural: el ejemplo de la producción de cecina de caballo de Villarramiel de Campos (Palencia)», en BAENA ESCUDEO, R. et al. (Coord). Investigando en rural. Ulzama Ediciones, Navarra, 389-398 pp.

García Galán, M. M. et al. (2006): «Las Denominaciones de Origen en Extremadura: una apuesta por la calidad», Boletín Económico de ICE, Información Comercial de España, n²889, 55-64.

García Royo, A. y Albisu Aguado, L. M. (2004): «Evolución de la industria agroalimentaria española en las dos últimas décadas», Economía industrial, n³55356, pp.197-210.

García Sanz, B. (2003): «La industria agroalimentaria y el desarrollo rural», $\mathrm{Pa}$ peles de economía española, nº6, pp.96-111.

García Villaverde, P. M. et al. (2001): «Análisis estratégico del sector agroalimentario en las regiones interiores», Revista española de estudios agrosociales y pesqueros, no191, p. 81-108.

Gómez Arias, J. T. y Bello Acebrón, L. (1996): «Las denominaciones de origen y otras señales de calidad en las estrategias de diferenciación de los productos agroalimentarios: una propuesta metodológica», Cuadernos aragoneses de economía, n², pp. 365-387. 
Gordo Gómez, P. (1989): La industria agroalimentaria en Castilla y León. Consejería de Economía y Hacienda de la Junta de Castilla y León, Valladolid, sin páginas.

Gordo Gómez, P. (1990): «Localización de las áreas de interés agroindustrial en Castilla y León» en actas del $2^{\circ}$ Congreso de Economía regional de Castilla y León, León, pp. 354-369.

Gordo Gómez, P. (2011): «El sector agroalimentario» en Fernández Arufe, J.E. y Ogando Canaval, J.O. (Dir), la economía de la provincia de Valladolid, pp. 469-494.

Jiménez Zarco, A. I. y Gómez Borja, M. A. (2002): «Las Denominaciones de Origen de Vinos de Castilla-La Mancha», Agricultura: Revista agropecuaria, $n^{\circ} 840,438-447$.

Jovellanos, G. M. De, (1979): Informe de la Sociedad Económica de Madrid al Real y Supremo Consejo de Castilla, en el Expediente de la Ley Agraria. Ediciones Cátedra, Madrid, 239 pp.

Juste Carrión, J. J. (2002): «Industria agroalimentaria y desarrollo socio rural: algunas reflexiones sobre el caso de Castilla y León», Anales de estudios económicos y empresariales, $\mathrm{n}^{\circ} 15$, pp. 189-214.

Juste CARRión, J. J. (2011): «Industria agroalimentaria, desarrollo rural y sistemas productivos locales en Castilla y León», Cuadernos de Estudios Agroalimentarios, $\mathrm{n}^{\circ} 2$, pp. 219-252.

Herreros Estébanez, F. (1984): Historia de Frechilla. Diputación Provincial de Palencia. Palencia, 438 pp.

Huetz De Lemps, A. (2005): Vinos y viñedos de Castilla y León. Colección Mundo Rural de la Junta de Castilla y León. Segovia, 683 pp.

Londoño FeRnándeZ, J. L. (2009): «La denominación de origen y el alcance de su protección». Revista la propiedad inmaterial, nº13, pp. 41-58.

Madoz, P. (1850): Diccionario Geográfico-Estadístico-Histórico de España y sus posesiones de Ultramar. Tomo XVI. Imprenta del Diccionario Geográfico-Estadístico-Histórico de D. Pascual Madoz, Madrid.

Molinero Hernando, F. et al. (2001): Inventario de productos agroalimentarios de calidad de Castilla y León. Colección Mundo Rural de la Junta de Castilla y León. Valladolid, 585 pp.

Pascual Ruiz-Valdepeñas, H. (2012): «El significado de la industria y de las nuevas infraestructuras en las estructura territorial» en DELGADO URRECHO, J. (ed.), Población y poblamiento en Castilla y León. Consejo Económico y Social de la Comunidad de Castilla y León. Valladolid, pp. 639-736.

Pérez-Bustamante Ilander, G. (1999): «Las denominaciones de origen e indicaciones geográficas en la Unión Europea su libre circulación y consideración de signos distintivos de calidad», Economía Aragonesa, nº8, pp.104-126. 
Pérez De Andrés, J. (1999): «Cecinas de Castilla y León». Informe elaborado para la Consejería de Agricultura y Ganadería. Dirección General de Producción e Industrias Agroalimentarias de la Junta de Castilla y León. Valladolid, sin páginas.

PRiETo, M. et al. (2008): «Concepto de calidad en la industria agroalimentaria». Interciencia: Revista de ciencia y tecnología de América, nº4, pp. 258-264.

Represa Fernández, M. F. y Helguera Quijada, J. (1992): «La evolución del primer espacio industrial en Valladolid: la dársena y el derrame del canal de Castilla (1836-1975)», Anales de estudios económicos y empresariales, nº7, pp. 321-352. Sánchez Hernández, J. L. (2003): «Capital exógeno y procesos de innovación en la industria vinícola de la Denominación de Origen Toro», Boletín de la A.G.E., nº 36, pp. 61-79. 